\title{
The oxygen radicals involved in the toxicity induced by parthenolide in MDA-MB-231 cells
}

\author{
DANIELA CARLISI ${ }^{1}$, ANTONELLA D'ANNEO ${ }^{2}$, ROBERTA MARTINEZ ${ }^{1}$, SONIA EMANUELE ${ }^{1}$, \\ GIUSEPPINA BUTTITTA ${ }^{1}$, RICCARDO DI FIORE ${ }^{2}$, RENZA VENTO $^{2,3}$, \\ GIOVANNI TESORIERE $^{2,3}$ and MARIANNA LAURICELLA ${ }^{1}$
}

\author{
${ }^{1}$ Laboratory of Biochemistry, Department of Experimental Biomedicine and Clinical Neurosciences, \\ and ${ }^{2}$ Laboratory of Biochemistry, Department of Biological, Chemical and Pharmaceutical Sciences and Technologies, \\ Polyclinic, University of Palermo, 90127 Palermo, Italy; ${ }^{3}$ Sbarro Institute for Cancer Research and Molecular Medicine, \\ College of Science and Technology, Temple University, Philadelphia, PA 19122, USA
}

Received February 26, 2014; Accepted April 22, 2014

DOI: 10.3892/or.2014.3212

\begin{abstract}
It has been shown that the sesquiterpene lactone parthenolide lowers the viability of MDA-MB-231 breast cancer cells, in correlation with oxidative stress. The present report examined the different radical species produced during parthenolide treatment and their possible role in the toxicity caused by the drug. Time course experiments showed that in the first phase of treatment $(0-8 \mathrm{~h})$, and in particular in the first $3 \mathrm{~h}$, parthenolide induced dichlorofluorescein (DCF) signal in a large percentage of cells, while dihydroethidium (DHE) signal was not stimulated. Since the effect on DCF signal was suppressed by apocynin and diphenyleneiodonium (DPI), two inhibitors of NADPH oxidase (NOX), we suggest that parthenolide rapidly stimulated NOX activity with production of superoxide anion $\left(\mathrm{O}_{2}^{-}\right)$, which was converted by superoxide dismutase 1 (SOD1) into hydrogen peroxide $\left(\mathrm{H}_{2} \mathrm{O}_{2}\right)$. In the second phase of treatment $(8-16 \mathrm{~h})$, parthenolide increased
\end{abstract}

Correspondence to: Professor Marianna Lauricella, Laboratory of Biochemistry, Department of Experimental Biomedicine and Clinical Neurosciences, Polyclinic, University of Palermo, Via del Vespro 129, 90127 Palermo, Italy

E-mail:marianna.lauricella@unipa.it

Abbreviations: DCF, dichlorofluorescein; DCFH-DA, 5-(and-6)carboxy-2',7'-dichlorodihydrofluorescein diacetate; DHE, dihydroethidium; DMSO, dimethyl sulfoxide; DPI, diphenyleneiodonium; $\Delta \psi \mathrm{m}$, mitochondrial membrane potential; $\mathrm{H}_{2} \mathrm{O}_{2}$, hydrogen peroxide; HPF, hydroxyphenyl fluorescein; hROS, highly reactive oxygen species; JNK, c-Jun N-terminal kinase; MnSOD, manganese superoxide dismutase; MTT, 3-(4,5-dimethylthiazol-2-yl)-2,5-diphenyltetrazolium bromide; NF- $\kappa \mathrm{B}$, nuclear factor $\kappa \mathrm{B}$; NO, nitric oxide; NOX, NADPH oxidase; $\mathrm{O}_{2}{ }^{-}$, superoxide anion; $\mathrm{PI}$, propidium iodide; $\mathrm{PN}$, parthenolide; ROS, reactive oxygen species; $\mathrm{SOD}$, superoxide dismutase

Key words: parthenolide, oxygen radicals, NADPH oxidase, breast cancer cells the number of positive cells to DHE signal. Since this event was not prevented by apocynin and DPI and was associated with positivity of cells to MitoSox Red, a fluorochrome used to detect mitochondrial production of $\mathrm{O}_{2}{ }^{--}$, we suggest that parthenolide induced production of $\mathrm{O}_{2}{ }^{--}$at the mitochondrial level independently by NOX activity in the second phase of treatment. Finally, in this phase, most cells became positive to hydroxyphenyl fluorescein (HPF) signal, a fluorescent probe to detect highly reactive oxygen species (hROS), such as hydroxyl radical and peroxynitrite. Therefore, parthenolide between 8-16 h of treatment induced generation of $\mathrm{O}_{2}{ }^{--}$and hROS, in close correlation with a marked reduction in cell viability.

\section{Introduction}

Reactive oxygen species (ROS) are produced in the cells during aerobic metabolism. At first, molecular oxygen can be reduced to form superoxide anion $\left(\mathrm{O}_{2}{ }^{-}\right)$by the activity of NADPH oxidase (NOX) $(1,2)$, a multicomponent enzyme, or by xanthine oxidase, lipoxygenase and mitochondrial oxidases (2). Subsequently, superoxide, a highly ROS (hROS), is converted by superoxide dismutase (SOD) $(3,4)$ to hydrogen peroxide $\left(\mathrm{H}_{2} \mathrm{O}_{2}\right)$, a more stable species, which can be reduced to water either by catalase or by glutathione peroxidase (2).

An excess of $\operatorname{ROS}\left(\mathrm{O}_{2}{ }^{--}\right.$and $\left.\mathrm{H}_{2} \mathrm{O}_{2}\right)$ is commonly referred to as oxidative stress. This condition, which is responsible for cell damage, can be induced by many diseases and a number of toxic agents (5).

Also, nitric oxide (NO) is implicated in pathological mechanisms. One of these mechanisms involves NO in a reaction with superoxide to form peroxynitrite (6) that is a potent oxidant. Peroxynitrite leads to lipid peroxidation and nitration of tyrosine residues in proteins with their inactivation (7).

Parthenolide, a sesquiterpene lactone found in Tanacetum parthenium, known for its anti-inflammatory activity, is currently considered an effective antitumour agent $(8,9)$. It has been shown that this drug exerts its effect by inducing generation of $\operatorname{ROS}(10)$ and inhibiting the nuclear factor $\kappa \mathrm{B}(\mathrm{NF}-\kappa \mathrm{B})$ (11). 
We have previously shown that parthenolide rapidly stimulates ROS generation in human osteosarcoma MG-63 and melanoma SK-MEL-28 cells (12) as well as in breast cancer MDA-MB-231 cells (13). Furthermore, it has been reported that parthenolide induces the activity of NOX in prostate cancer PC3 cells (14). Recently, we demonstrated that the drug stimulates NOX activity with $\mathrm{O}_{2}{ }^{--}$production in MDA-MB-231 cells as well $(13,15)$, which could be responsible for the toxic effects caused by the drug. These effects consist in the depletion of thiol groups and glutathione, NF- $\kappa \mathrm{B}$ inhibition, c-Jun $\mathrm{N}$-terminal kinase (JNK) activation, dissipation of mitochondrial membrane potential $(\Delta \psi \mathrm{m})$ and necrotic effects $(12,13)$.

The aim of the present report was to study the production of different oxygen species induced by parthenolide, such as $\mathrm{H}_{2} \mathrm{O}_{2}, \mathrm{O}_{2}{ }^{-}$, and peroxynitrite, in order to demonstrate the relationships between these compounds and the role exerted by parthenolide in the induction of toxicity in MDA-MB-231 cells.

\section{Materials and methods}

Chemicals and reagents. Parthenolide was supplied by SigmaAldrich (Milan, Italy). Stock solution of parthenolide was prepared in dimethyl sulfoxide (DMSO) and diluted to a final concentration in the culture medium. Final concentration of DMSO employed as vehicle never exceeded $0.04 \%$ and had no discernible effects on MDA-MB-231 cells in comparison with the control. Unless otherwise indicated, all reagents were purchased from Sigma-Aldrich.

Cell cultures. Human breast carcinoma MDA-MB-231 cells were provided by Istituto Scientifico Tumori (Genoa, Italy). The cell line was grown as monolayer in Dulbecco's modified Eagle's medium (DMEM) supplemented with $10 \%$ (v/v) heat inactivated fetal calf serum (FCS), $2 \mathrm{mM}$ glutamine and $1 \%$ non-essential amino acids, at $37^{\circ} \mathrm{C}$ in a humidified atmosphere containing $5 \% \mathrm{CO}_{2}$. After plating on 96 - or 6 -well plates, cells were allowed to adhere overnight and were then treated with chemicals or vehicle only.

Analysis of cell viability and cell necrosis. For these studies, the cells $\left(8 \times 10^{3}\right)$ were seeded into 96 -well plates. Twenty-four hours after seeding, cells were treated with drugs for the time indicated in the Results. Cell viability was determined by the 3-(4,5-dimethylthiazol-2-yl)-2,5-diphenyltetrazolium bromide (MTT) colorimetric assay as previously reported (16). MTT is reduced to purple formazan in the mitochondria of living cells. The absorbance of the formazan was measured at $570 \mathrm{~nm}$, with $630 \mathrm{~nm}$ as a reference wavelength using an automatic ELISA plate reader (Opsys MR; Dynex Technologies, Chantilly, VA, USA). After treatment with the drugs, cell survival was estimated as a percentage of the value of the vehicle-treated control.

To determine membrane damage, the cells were stained with propidium iodide (PI), as previously reported (13). In particular, cells $\left(8 \times 10^{3} /\right.$ well $)$ were incubated in culture medium and treated for various times with parthenolide, and PI (2.0 $\mu \mathrm{g} / \mathrm{ml}$ medium) was then added and the incubation was protracted for an additional $15 \mathrm{~min}$. At the end, cell morphology was visualized by a Leica DMR microscope equipped with a DC300F camera (Leica Microsystems, Wetzlar, Germany) using an appropriate filter to examine PI (rhodamine filter with excitation wavelength of $596 \mathrm{~nm}$ and emission wavelength of $620 \mathrm{~nm}$ ). All the images were acquired by Leica Q-Fluoro Software. Cells with red fluorescence were counted and normalized to the total number of cells/field to calculate the percentage of PI-positive cells. Five fields/condition were analysed.

Flow cytometric analysis. MDA-MB-231 cells (10\%/well) were incubated with parthenolide and other effectors for various times. At the end, the cells were trypsinized, collected, washed with PBS and incubated with fluorescent probes.

DCFH-DA analysis. Generation of intracellular radicals was measured using 5-(and-6)-carboxy-2',7'-dichlorodihydrofluorescein diacetate (DCFH-DA; Molecular Probe, Life Technologies, Eugene, OR, USA), a fluorochrome that passively diffuses into the cells. After cleavage of acetate groups by intracellular esterases, a fluorescent adduct (DCF) is produced by oxidation. To analyse DCF signal, the cells were incubated with $50 \mu \mathrm{M}$ DCFH-DA in Hank's balanced salt solution (HBSS) for $30 \mathrm{~min}$ at $37^{\circ} \mathrm{C}$ in darkness.

DHE analysis. $\mathrm{O}_{2}{ }^{--}$production was assessed by dihydroethidium (DHE) staining. The fluorochrome DHE is oxidized by superoxide to fluorescent ethidium that intercalates with nuclear DNA, staining the nucleus with a bright red fluorescence. After treatment with parthenolide, the cells were incubated with $20 \mu \mathrm{M}$ DHE in PBS for $15 \mathrm{~min}$ at $37^{\circ} \mathrm{C}$ in darkness.

MitoSox Red analysis. To detect mitochondrial production of $\mathrm{O}_{2}{ }^{-}$, MitoSox Red fluorochrome was used (Molecular Probe, Life Technologies). MitoSox Red is a mitochondria-targeted form of DHE that is relatively specific for $\mathrm{O}_{2}^{-{ }^{-}}$and undergoes oxidation to form a DNA-binding red fluorescent product (17). After treatment, the cells were incubated with $5 \mu \mathrm{M}$ MitoSox Red in HBSS buffer for $10 \mathrm{~min}$ at $37^{\circ} \mathrm{C}$ in the dark.

HPF analysis. Hydroxyphenyl fluorescein (HPF; Enzo Life Sciences Inc., Farmingdale, NY, USA) was employed to detect hROS). HPF is a cell permeable minimally fluorescent dye, which reacts with hROS $(\cdot \mathrm{OH}$, ONOO- and $-\mathrm{OCl})$ and is converted to fluorescein, which exhibits strong, dose-dependent fluorescence (18). In this case, the cells after the treatment were incubated with $10 \mu \mathrm{M}$ HPF in HBSS for $1 \mathrm{~h}$ at $37^{\circ} \mathrm{C}$ in the dark. Then, cells were collected and resuspended in $500 \mu \mathrm{l}$ HBSS.

All analyses were performed using a Beckman Coulter Epics XL flow cytometer (Beckman Coulter, Brea, CA, USA) with appropriate filters. For DCF and HPF signals, FITC filter was used with excitation wavelength of $480 \mathrm{~nm}$ and emission wavelength of $525 \mathrm{~nm}$. For DHE and MitoSox Red, rhodamine filter was used with excitation wavelength of $518 \mathrm{~nm}$ and emission wavelength of $605 \mathrm{~nm}$. All the acquired data were analysed by EXPO32 software.

Western blot analysis. For these studies, after treatment, cells were washed in PBS, lysed for $30 \mathrm{~min}$ at $4^{\circ} \mathrm{C}$ in ice-cold lysis 
buffer (1\% NP-40, 0.1\% SDS and 0.5\% sodium deoxycholate in PBS), containing protease inhibitor cocktail and sonicated three times for $10 \mathrm{sec}$. Then, protein concentration was determined by Lowry assay (19). Equal amounts of protein samples (50 $\mu \mathrm{g} / \mathrm{lane}$ ) were subjected to SDS-polyacrylamide gel electrophoresis, then blotted to a nitrocellulose membrane.

All western blot analyses were performed using specific antibodies obtained from Santa Cruz Biotechnology (Santa Cruz, CA, USA). Detection was developed using secondary antibodies conjugated with alkaline phosphatase.

Protein bands were visualized using 5-bromo-4-chloro3-indolyl phosphate and nitro blue tetrazolium (Promega Italia, Milan, Italy) and their intensity was quantified by densitometric analysis using SMX Image software (Bio-Rad Laboratories Srl, Segrate, Italy).

Statistical analysis. Results are presented as means \pm standard error. Data were analysed using the Student's t-test.

\section{Results}

Effects induced by parthenolide on the ROS. In order to establish the effect exerted by parthenolide on the generation of radical species, we analysed the changes induced by parthenolide treatment on four different fluorescent signals, DCF, DHE, MitoSox Red and HPF (Fig. 1).

DCFH-DA was used as a fluorescent probe for ROS. Although this probe is widely used for $\mathrm{H}_{2} \mathrm{O}_{2}$, it lacks specificity among ROS and reacts strongly with hROS, such as hydroxyl radicals and peroxynitrite (18).

The time course of the parthenolide effect exerted on DCF signal is reported in Fig. 1A. It was observed that in the first hours of treatment (1-3 h) with $25 \mu \mathrm{M}$ parthenolide most cells $(>90 \%$ ) were positive to DCF signal. After $3 \mathrm{~h}$, this percentage declined progressively with the time of treatment so that at $8 \mathrm{~h}$ only $40 \%$ of cells were positive to DCF. After $8 \mathrm{~h}$, DCF signal increased again until $16 \mathrm{~h}$ of treatment, when DCF-positive cells reached $70 \%$ of the total cells.

The fluorochrome DHE was used to assess superoxide radical production. The time course of the effect exerted by parthenolide on DHE signal is shown in Fig. 1B. We observed that the percentage of DHE-positive cells was very modest in the first $5 \mathrm{~h}$ of treatment, then progressively increased in the second phase of treatment (8-16 h), reaching a level near $75 \%$ at $16 \mathrm{~h}$.

MitoSox Red was used to ascertain superoxide production at the mitochondrial level. As shown in Fig. 1C, the percentage of cells positive to MitoSox Red progressively increased from 8 to $16 \mathrm{~h}$ of incubation. Results reported for MitoSox Red are similar to those ascertained for DHE signal. This finding suggests that $\mathrm{O}_{2}{ }^{-}$assayed in the second phase of treatment with parthenolide was primarily produced at the mitochondrial level.

HPF is a fluorescent probe used to detect selectively hROS, such as hydroxyl radical and peroxynitrite, but not $\mathrm{H}_{2} \mathrm{O}_{2}, \mathrm{NO}$ and superoxide (18). As shown in Fig. 1D, positivity to HPF signal was particularly observed in the second phase of treatment $(8-16 \mathrm{~h})$, reaching the maximum at $16 \mathrm{~h}$ when $75 \%$ of cells were positive to this signal. This result demonstrated that parthenolide in the second phase of treatment stimulated the production of hydroxyl radical and peroxynitrite.
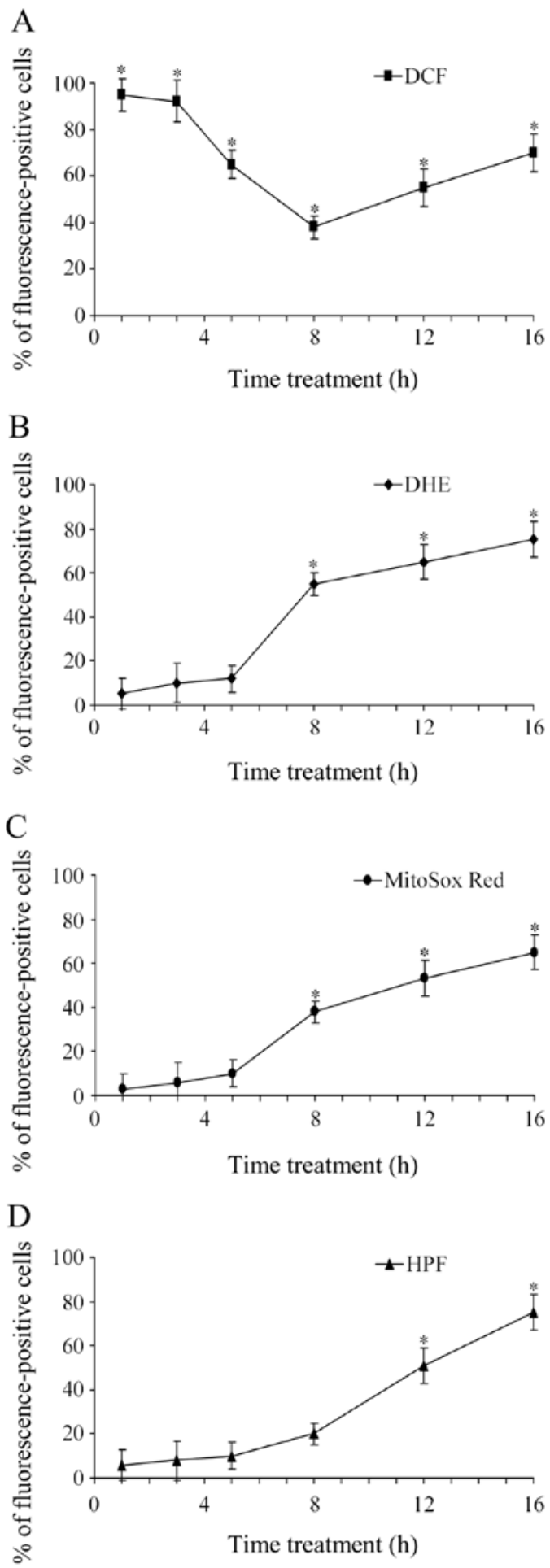

Figure 1. Time course of cytofluorimetric analyses in MDA-MB-231 cells treated with parthenolide. Cells $\left(10^{5}\right)$ were seeded in 6-well plates and treated with $25 \mu \mathrm{M}$ parthenolide for different times. Analyses were performed at $1,3,5,8,12$ and $16 \mathrm{~h}$, as reported in Materials and methods, using four different fluorescent probes: (A) dichlorofluorescein (DCF), (B) dihydroethidium (DHE), (C) MitoSox Red and (D) hydroxyphenyl fluorescein (HPF). Analyses were performed by a Beckman Coulter cytometer using the EXPO32 software. All the results are expressed as percentage of fluorescent cells and are the mean $\pm \mathrm{SE}$ of three independent experiments. ${ }^{*} \mathrm{P}<0.01$ vs. untreated control.

Influence of apocynin and DPI on the effects exerted by parthenolide on ROS generation. Fig. 2 shows the influence exerted by apocynin and DPI, two effective inhibitors of NOX, 
A

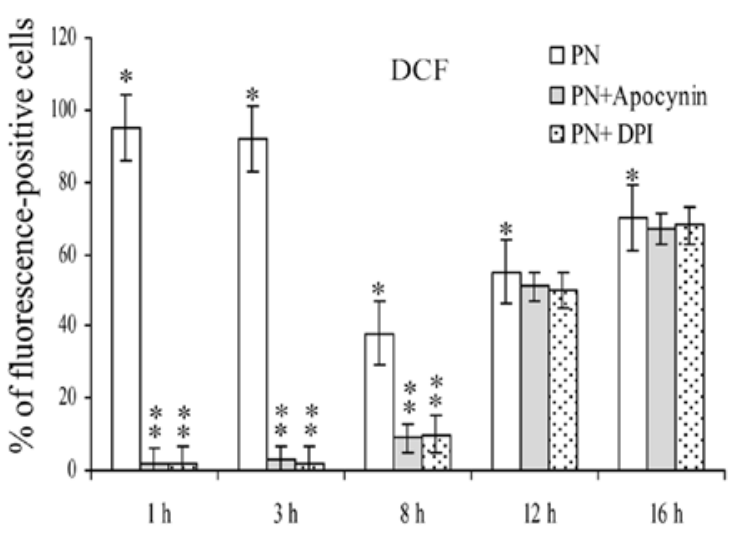

$\mathrm{B}$

DHE
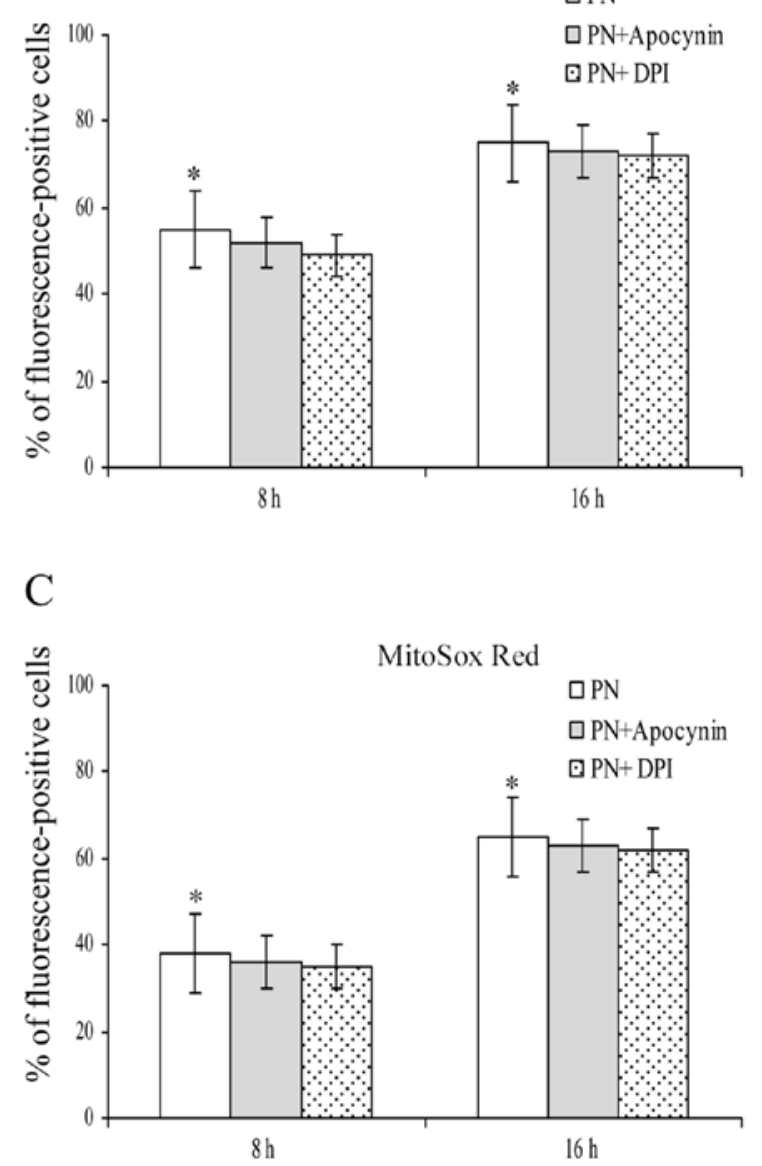

Figure 2. The effects of NOX inhibitors on DCF, DHE and MitoSox Red signals. Cells were treated for the indicated times with $25 \mu \mathrm{M}$ parthenolide without or with $100 \mu \mathrm{M}$ apocynin or $10 \mu \mathrm{M}$ DPI, DCF, DHE and MitoSox Red signals were estimated as described in Materials and methods. The results are the mean $\pm \mathrm{SE}$ of three independent experiments. ${ }^{*} \mathrm{P}<0.01$ vs. untreated control. ${ }^{* *} \mathrm{P}<0.01$ vs. cells treated with only parthenolide. NOX, NADPH oxidase; DCF, dichlorofluorescein; DHF, dihydroethidium; DPI, diphenyleneiodonium.

on the effects induced by parthenolide on ROS generation. It is of note that both inhibitors completely suppressed the effects on DCF signal found at 1 and $3 \mathrm{~h}$ of treatment with parthenolide. In addition, the inhibitors also markedly diminished the effect exerted on DCF signal at $8 \mathrm{~h}$ of treatment, whereas their effect was very modest, at 12 and 16 h of treatment (Fig. 2A).
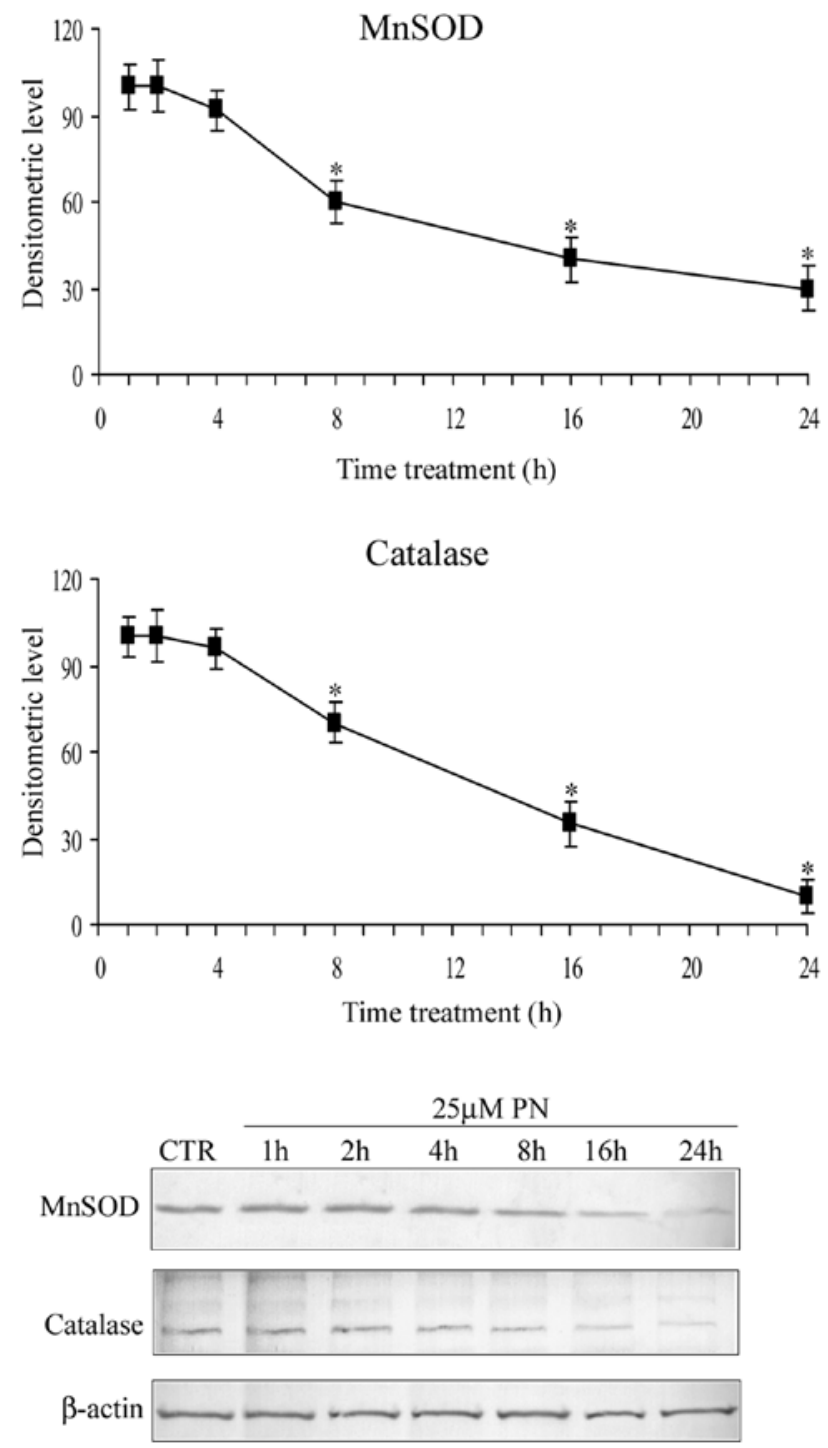

Figure 3. The effect of parthenolide on the level of MnSOD and catalase. MDA-MB-231 cells ( $2 \times 10^{5}$ cells/well) were treated with $25 \mu \mathrm{M}$ parthenolide for the indicated times. At the end, cell extracts were prepared as described in Materials and methods and submitted to western blot analysis using specific antibodies directed against MnSOD or catalase. The correct protein loading was ascertained by immunoblotting for $\beta$-actin. Densitometric evaluation is reported in the upper panel; the values are the means of three independent experiments $\pm \mathrm{SE}$. ${ }^{*} \mathrm{P}<0.01$ vs. untreated control. MnSOD, manganese superoxide dismutase.

Fig. 2B and C show that apocynin and DPI did not modify the effect induced by parthenolide on both DHE and MitoSox Red assays at 8 and $16 \mathrm{~h}$. These results demonstrate that $\mathrm{O}_{2}{ }^{-}$ detected by these fluorochromes was not produced by NOX activity.

Time course of the parthenolide effect on manganese superoxide dismutase (MnSOD) and catalase levels. Fig. 3 shows the time course of the parthenolide effect on the level of MnSOD (SOD2) and catalase. The results demonstrated that in the first hours (0-4 h) of treatment, parthenolide did not modify the level of MnSOD and catalase, whereas after $4 \mathrm{~h}$, the level of the two proteins progressively diminished and at $16 \mathrm{~h}$ it was reduced to $\sim 40 \%$ of the control value. These results are in accordance with the previous observations of Sun et al (14). 


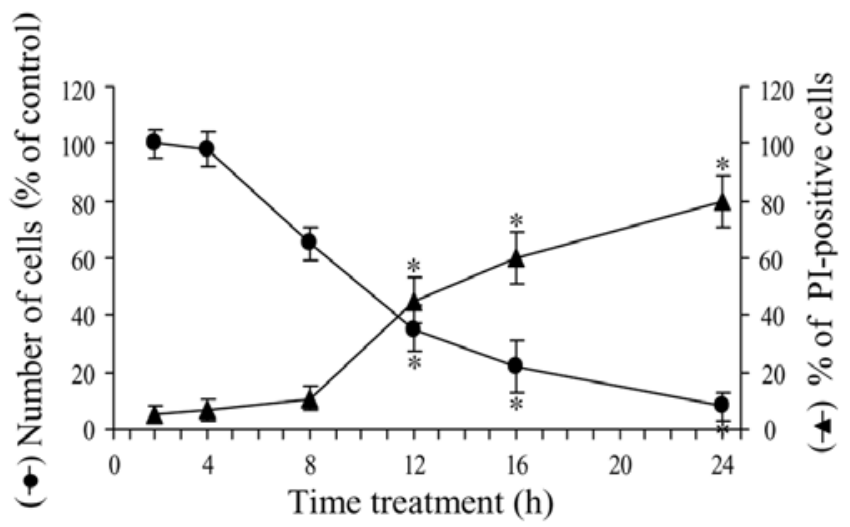

Figure 4. The effect of parthenolide on cell viability and cell necrosis MDA-MB-231 cells (8x10\%3ell) were treated for various times with $25 \mu \mathrm{M}$ parthenolide. ( $\bullet$ Cytotoxic effects exerted by parthenolide on cell viability. Cell viability was assessed by MTT assay, as reported in Materials and methods. (ム) Cell necrosis determined by propidium iodide (PI) staining After treatment, the cells were incubated for $15 \mathrm{~min}$ with PI $(2.0 \mu \mathrm{g} / \mathrm{ml}$ medium; red fluorescence) and the percentage of PI-positive cells was ascertained as described in Materials and methods. The values are the means of three independent experiments $\pm \mathrm{SE}$. ${ }^{*} \mathrm{P}<0.01$ vs. untreated control.

Time course of the parthenolide effect on cell viability. Fig. 4 shows the time course of the effect of parthenolide on cell viability. In particular, in the first $4 \mathrm{~h}$ of treatment, viability was reduced by only $4 \%$, then the effect increased and at $8 \mathrm{~h}$ viability decreased to $65 \%$ of control. In the second phase of treatment, viability rapidly diminished and at $16 \mathrm{~h}$ was equal to $22 \%$ and at $24 \mathrm{~h}$ to only $8 \%$.

To ascertain the effect of parthenolide on the production of necrotic cells, we employed PI, a cell-impermeable nuclear dye, which stains the nuclei of cells that have lost plasma membrane integrity and are considered necrotic. As shown in Fig. 4, the number of PI-positive cells increased slowly in the first phase of treatment (10\% at $8 \mathrm{~h}$ ). Between 8 and $20 \mathrm{~h}$, the increment was more rapid, reaching a level of $60 \%$ at $16 \mathrm{~h}$ and $80 \%$ at $24 \mathrm{~h}$ of treatment.

\section{Discussion}

In previous studies $(13,15)$, we showed that parthenolide induces generation of ROS in MDA-MB-231 cells. The aim of the present study was to individuate the ROS produced under parthenolide treatment to specify the modalities of their production and the role exerted in the induction of cell death.

In order to clarify these aspects, at first we studied the effects exerted by $25 \mu \mathrm{M}$ parthenolide during $24 \mathrm{~h}$ of treatment on the viability of MDA-MB-231 cells. It was shown that in the first $4 \mathrm{~h}$ of treatment, the effect was very modest, while a marked reduction of the cell number was observed in the second phase of incubation (8-16 h).

Flow cytometric analysis of cellular ROS was performed in treated cells using fluorescent probes. DCFH-DA detects not only $\mathrm{H}_{2} \mathrm{O}_{2}$, but also hROS, such as hydroxyl radical and peroxynitrite, while DHE detects primarily $\mathrm{O}_{2}{ }^{\circ}$.

It was observed that most of the cells were positive to DCF signal already at 1-3 $\mathrm{h}$ of treatment. Since this effect was suppressed by the addition of either apocynin or DPI, two effective inhibitors of NOX activity, we suggest that parthenolide, in line with previous findings $(13,15)$, stimulated NOX activity, inducing production of $\mathrm{O}_{2}{ }^{--}$, which was rapidly dismutated by SOD1 to produce $\mathrm{H}_{2} \mathrm{O}_{2}$. Also, at $8 \mathrm{~h}$, apocynin and DPI exerted a marked inhibitory effect on DCF signal. Therefore, we conclude that in the first phase of treatment, the principal effect of parthenolide consists in the activation of NOX, followed by involvement of SOD1 with production of $\mathrm{H}_{2} \mathrm{O}_{2}$. This conclusion is also supported by the consideration that in this phase hROS were not produced, as indicated by the results obtained with HPF analysis (Fig. 1D).

DHE analysis showed that parthenolide stimulated this signal only in the second phase of treatment. $\mathrm{O}_{2}{ }^{\circ}$, assayed by DHE analysis, was not produced by NOX activity since the signal was not diminished by the addition of either apocynin or DPI. Therefore, it seems likely that $\mathrm{O}_{2}{ }^{--}$arises from mitochondrial activity, as suggested by positivity observed using MitoSox Red fluorochrome. It is possible that $\mathrm{H}_{2} \mathrm{O}_{2}$ can also be produced in this second phase of treatment. However, as DCF signal at 12 and $16 \mathrm{~h}$ was not inhibited by apocynin and DPI, we exclude that in this phase generation of $\mathrm{H}_{2} \mathrm{O}_{2}$ can be a consequence of activation of NOX, unlike the effect observed in the first hours of treatment.

Our results clearly demonstrate that parthenolide induced, in this second phase, production of hROS (hydroxyl radical and peroxynitrite), as suggested by the results of HPF analysis. In this phase, as previously ascertained by us (13), parthenolide caused mitochondrial dysfunction with a marked fall in $\Delta \psi \mathrm{m}$. Mitochondrial damage could be responsible for the production of either $\mathrm{O}_{2}{ }^{--}$and hROS. In particular, peroxynitrite could be produced by a specific reaction between $\mathrm{O}_{2}{ }^{--}$and $\mathrm{NO}(6)$ and could contribute to positivity found with both DCF and HPF signals in the second phase of incubation. The marked decrement in the level of both MnSOD and catalase, found in this phase of treatment, can contribute to determine the rise of $\mathrm{O}_{2}{ }^{-}$ and hROS. Finally, it is interesting to note that peroxynitrite and hydroxyl radical can in turn induce mitochondrial damage and further production of ROS (6).

A comparison between the time course of the parthenolide effect on cell viability and the production of ROS leads to the following conclusions: i) in a first phase of treatment (0-8 h), and in particular in the first $4 \mathrm{~h}$, the effect on cell viability was very modest, while most of the cells were positive to DCF signal owing to the production of $\mathrm{H}_{2} \mathrm{O}_{2}$; and ii) in the second phase (8-16 h), a strong effect on cell viability was observed, just when mitochondrial damage leads to the production of $\mathrm{O}_{2}{ }^{\circ-}$ and hROS. These results suggest that $\mathrm{O}_{2}{ }^{\circ-}$ and hROS may play a central role in the induction of cell death by parthenolide treatment.

\section{Acknowledgements}

The present study was supported by grants from the Italian Ministry of Education, University and Research (MIUR) ex-60\%, 2010; the European Regional Development Fund, European Territorial Cooperation 2007-2013, CCI 2007 CB 163 PO 037, OP Italia-Malta 2007-2013. Dr D. Carlisi is a recipient of a grant by the Italian Ministry of Education, University and Research (MIUR). Drs R. Martinez and G. Buttitta are $\mathrm{PhD}$ students of Doctorate in Biomedicine and Clinical Neuroscience supported by the Italian Ministry of Education, University and Research (MIUR). 


\section{References}

1. Nauseef WM: Detection of superoxide anion and hydrogen peroxide production by cellular NADPH oxidases. Biochim Biophys Acta 1840: 757-767, 2014.

2. Paletta-Silva R, Rocco-Machado N and Meyer-Fernandes JR: NADPH oxidase biology and the regulation of tyrosine kinase receptor signaling and cancer drug cytotoxicity. Int J Mol Sci 14 3683-3704, 2013.

3. Fukai T and Fukai MU: Superoxide dismutases: role in redox signaling, vascular function, and diseases. Antioxid Redox Signal 15: 1583-1606, 2011.

4. Landis GN and Tower J: Superoxide dismutase evolution and life span regulation. Mech Ageing Dev 126: 365-337, 2005.

5. Bartosz G: Reactive oxygen species: destroyers or messengers? Biochem Pharmacol 77: 1303-1315, 2009.

6. Zunino SJ, Ducore JM and Storms DH: Parthenolide induces significant apoptosis and production of reactive oxygen species in high-risk pre-B leukemia cells. Cancer Lett 254: 119-127, 2007.

7. Pacher P,Beckman JS and Liaudet L: Nitric oxide and peroxynitrite in health and disease. Physiol Rev 87: 315-424, 2007.

8. Ghantous A, Sinjab A, Herceg Z and Darwiche N: Parthenolide: from plant shoots to cancer roots. Drug Discov Today 18 894-905, 2013.

9. Kreuger MR, Grootjans S, Biavatti MW, Vandenabeele P and D'Herde K: Sesquiterpene lactones as drugs with multiple targets in cancer treatment: focus on parthenolide. Anticancer Drugs 23: 883-896, 2012

10. Wang W, Adachi M, Kawamura R, et al: Parthenolide-induced apoptosis in multiple myeloma cells involves reactive oxygen species generation and cell sensitivity depends on catalase activity. Apoptosis 11: 2225-2235, 2006.

11. Nakabayashi $H$ and Shimizu K: Involvement of Akt/NF- $\kappa B$ pathway in antitumor effects of parthenolide on glioblastoma cells in vitro and in vivo. BMC Cancer 12: 453, 2012.
12. D'Anneo A, Carlisi D, Lauricella M, Emanuele S, Di Fiore R, Vento R and Tesoriere G: Parthenolide induces caspase-independent and AIF-mediated cell death in human osteosarcoma and melanoma cells. J Cell Physiol 228: 952-967, 2013.

13. D'Anneo A, Carlisi D, Lauricella M, Martinez R, Emanuele S, Vento R and Tesoriere G: Parthenolide generates reactive oxygen species and autophagy in MDA-MB-231 cells. A soluble parthenolide analogue inhibits tumour growth and metastasis in a xenograft model of breast cancer. Cell Death Dis 4: e891, 2013.

14. Sun Y, St Clair DK, Xu Y, Crooks PA and St Clair WH: A NADPH oxidase-dependent redox signaling pathway mediates the selective radiosensitization effect of parthenolide in prostate cancer cells. Cancer Res 70: 2880-2890, 2010.

15. D'Anneo A, Carlisi D, Emanuele S, Buttitta G, Vento R, Tesoriere $\mathrm{G}$ and Lauricella M: Parthenolide induces superoxide anion production by stimulating EGF receptor in MDA-MB-231 breast cancer cells. Int J Oncol 43: 1895-1900, 2013.

16. Carlisi D, D'Anneo A, Angileri L, Lauricella M, Emanuele S, Vento R and Tesoriere G: Parthenolide sensitizes hepatocellular carcinoma cells to TRAIL by inducing the expression of death receptors through inhibition of STAT3 activation. J Cell Physiol 226: 1632-1641, 2011.

17. Han Z, Varadharaj S, Giedt RJ, Zweier JL, Szeto HH and Alevriadou BR: Mitochondria-derived reactive oxygen species mediate heme oxygenase- 1 expression in sheared endothelial cells. J Pharmacol Exp Ther 329: 94-101, 2009.

18. Setsukinai K, Urano Y, Kakinuma K, Majima H and Nagano T: Development of novel fluorescence probes that can reliably detect reactive oxygen species and distinguish specific species. J Biol Chem 278: 3170-3175, 2003.

19. Lowry OH, Rosebrough NJ, Farr AL and Randall RJ: Protein measurement with the folin phenol reagent. J Biol Chem 193: 265-275, 1951 . 